\section{ORIGINAL RESEARCH}

\author{
J.L. Leach \\ K. Meyer
}

B.V. Jones

T.A. Tomsick

\title{
Large Arachnoid Granulations Involving the Dorsal Superior Sagittal Sinus: Findings on MR Imaging and MR Venography
}

\begin{abstract}
BACKGROUND AND PURPOSE: Large arachnoid granulations (AG) within the dorsal superior sagittal sinus (SSS) have been incompletely characterized and can be confused with pathology. This report reviews the characteristics of these anatomic structures to establish common imaging features that allow differentiation from pathology.
\end{abstract}

MATERIALS AND METHODS: Twelve cases of large AG in the dorsal SSS are presented, identified by MR imaging. Signal intensity characteristics, size, location, venographic appearance, and association with adjacent venous and osseous structures were documented.

RESULTS: A defect in the dura of the SSS was seen in all of the cases communicating with the subjacent subarachnoid space. The average size of the AG was $8.1 \times 9.4 \times 10.0 \mathrm{~mm}$ (range, 4-19 $\mathrm{mm})$. Ten produced calvarial remodeling, and 11 were in the direct vicinity of the lambda. On T2-weighted images, all were hyperintense to the brain. On T1-weighted images, 8 were hypointense and 4 were hypointense with mixed areas of isointense signal intensity. All of the AGs were associated with cortical venous structures entering the sinus. On MR venography, AGs appeared as focal protrusions into the sinus, displacing, distorting, and narrowing the sinus lumen. Seven patients had headache without other visible cause on MR imaging, and 4 were initially interpreted as thrombosis or tumor.

CONCLUSION: Large AGs can occur in the dorsal SSS. They are well-defined projections of the subarachnoid space into the sinus, can cause luminal narrowing and calvarial remodeling, and have typical signal intensity characteristics, position, and morphology differentiating them from other pathology. Association with patient symptoms is uncertain.

A rachnoid granulations (AGs) are normal structures that can be demonstrated on CT and MR imaging. ${ }^{1}$ They typically are identified as CSF attenuation or signal intensity protuberances projecting into the lumen of the dural sinuses. ${ }^{1}$ Although most commonly identified on standard imaging studies in the midlateral transverse sinuses (TSs), ${ }^{2,3}$ when more detailed high-resolution MR imaging examinations with contrast are used, they can be identified throughout the dural sinuses. ${ }^{4}$ Rarely, large AGs have been described in the dorsal (posterior inferior) superior sagittal sinus (SSS) on imaging ${ }^{1,5}$ and on anatomic assessment. ${ }^{6}$ Because of their infrequency and large size, they can be misdiagnosed as a thrombus or tumor in this location. ${ }^{5}$ We have identified 12 cases of large AGs in the dorsal SSS on MR imaging (1.5T and 3T), and describe their appearance on standard MR pulse sequences, time-of-flight MR venography (MRV; TOF-MRV) and contrast-enhanced MRV (CE-MRV). We compared these cases with the few cases reported previously in the literature and established common imaging features that allow differentiation from pathology.

Received November 28, 2007; accepted after revision February 26, 2008.

From the Department of Radiology (J.L.L., K.M., B.V.J., T.A.T.), University of Cincinnati College of Medicine, Cincinnati, Ohio; Department of Radiology and Medical Imaging (J.L.L., B.V.J.), Cincinnati Children's Hospital Medical Center, Cincinnati, Ohio; and The Neuroscience Institute (J.L.L., T.A.T.), Cincinnati, Ohio.

Please address correspondence to James L. Leach, Department of Radiology, Cincinnati Children's Hospital Medical Center, 3333 Burnet Ave, Cincinnati, OH 45229; e-mail: james.leach@cchmc.org

indicates article with supplemental on-line table.

DOI 10.3174/ajnr.A1093

\section{Materials and Methods}

Twelve cases of large AGs in the dorsal SSS were identified during clinical assessment of MR imaging from 2005 to 2006. The diagnosis was based by using criteria established from previously reported cases of AGs on MR imaging. ${ }^{1-3,5}$ These cases came to our attention during routine daily imaging readout sessions and during consultations with other radiologists or clinicians in the cases in which alternative pathologic diagnoses were offered on initial interpretation. A radiology report search for the term "arachnoid granulations" was also performed over this time interval to identify other cases in the dorsal SSS. There was no cutoff value of size below which AGs in this region were excluded from the study. AGs are very well-defined CSF-like signal intensity protuberances extending into the dural sinus commonly associated with adjacent entering cortical veins. They do not exhibit signal intensity or enhancement characteristics suggestive of a thrombus or tumor. ${ }^{1}$ Additional features are outlined in the Results section.

\section{Imaging Parameters}

MR imaging was performed at 1.5T ( 6 cases), $3 \mathrm{~T}$ (5 cases), and $0.7 \mathrm{~T}$ and 3T ( 1 case; Table 1). Five cases also had CT imaging (3 with contrast), 4 cases had TOF-MRV, and 2 cases had CE-MRV.

MR imaging included an axial fast spin-echo T2-weighted sequence (FSE T2WI; TR, 3000-4000 ms; TE, 80-123.6 ms; echo-train length, 12), axial fluid-attenuated inversion recovery sequence (FLAIR; TR, 10,002-10,004 ms; TE, 123.4-142.0 ms; inversion time, $2200 \mathrm{~ms}$ ), diffusion-weighted imaging (DWI; echo-planar imaging, TR, 11,700 ms; TE, minimum; $b=1000 ; 3$ directions and b0 image), and an axial spin-echo T1-weighted sequence (T1WI; TR, 350-400 $\mathrm{ms}$; TE, 8-9 ms). Section thickness was $4 \mathrm{~mm}$ with no intersection gap for these sequences. Postcontrast T1-weighted images (CE T1WI, after intravenous administration of $0.1 \mathrm{~mL} / \mathrm{kg}$ of gadolinium) were also 


\begin{tabular}{|c|c|c|c|c|c|c|c|c|c|c|c|c|c|}
\hline Age & Sex & FS & MRV & Size, cm & $\begin{array}{l}\text { Distance Above } \\
\text { Torcular, cm }\end{array}$ & T1WI & T2WI & FLAIR & DWI & $\begin{array}{l}\text { Location } \\
\text { Relative to } \\
\qquad \lambda\end{array}$ & $\underset{\%}{\text { Stenosis, }}$ & Septation & Clinical \\
\hline 64 & $\mathrm{~F}$ & $3 \mathrm{~T}$ & & $1.2 \times 0.7 \times 1.1$ & 5.1 & Mixed & Hyper & Iso & Hуро & $\lambda$ & 20 & Yes & $\begin{array}{l}\text { MS follow-up, right leg } \\
\text { weakness, initially } \\
\text { called meningioma }\end{array}$ \\
\hline 42 & $\mathrm{~F}$ & $3 \mathrm{~T}$ & & $0.6 \times 0.7 \times 0.8$ & 5.1 & Mixed & Hyper & Iso & Нуро & $\lambda$ & 60 & Yes & $\begin{array}{l}\text { Right temporal } \\
\text { headaches }\end{array}$ \\
\hline 42 & $\mathrm{~F}$ & 3T-MRV & $\mathrm{T}, \mathrm{C}$ & $1.1 \times 1.1 \times 1.8$ & 3.9 & Mixed & Hyper & Iso & Нуро & $-2 \mathrm{~mm}$ & 86 & Yes & $\begin{array}{l}\text { Headache, initially } \\
\text { called thrombosis, } \\
\text { 0.7T-MR imaging }\end{array}$ \\
\hline 35 & $\mathrm{~F}$ & $1.5 \mathrm{~T}$ & & $1.1 \times 1.8 \times 1.9$ & 5.8 & Нуро & Hyper & Iso & Нypo & $\lambda$ & 60 & Yes & Left temporal headache \\
\hline 42 & M & $1.5 \mathrm{~T}$ & & $0.2 \times 0.3 \times 0.4$ & 5.9 & Нyро & Hyper & Iso & Нyро & $\lambda$ & 50 & No & Headache \\
\hline 28 & M & $3 \mathrm{~T}$ & $\mathrm{~T}, \mathrm{C}$ & $0.8 \times 0.9 \times 1.1$ & 5.2 & Mixed & Hyper & Iso & Нуро & $\lambda$ & 50 & No & $\begin{array}{l}\text { Seizures right frontal } \\
\text { glioma }\end{array}$ \\
\hline 52 & M & $3 \mathrm{~T}$ & & $0.7 \times 1.1 \times 1.7$ & 3.0 & Нуро & Hyper & Iso & Нypo & $-2 \mathrm{~mm}$ & 86 & Yes & Headaches \\
\hline 57 & M & $1.5 \mathrm{~T}$ & T & $0.4 \times 0.6 \times 0.6$ & 6.2 & Нуро & Hyper & Нуро & Нуро & $+12 \mathrm{~mm}$ & 50 & No & Ischemic stroke \\
\hline 45 & $F$ & $1.5 \mathrm{~T}$ & & $0.4 \times 0.6 \times 0.6$ & 3.5 & Нуро & Hyper & Нуро & Нуро & $\lambda$ & 40 & No & $\begin{array}{l}\text { Headache, Chiari I, } \\
\text { initially called } \\
\text { thrombosis }\end{array}$ \\
\hline 18 & $F$ & $3 \mathrm{~T}$ & & $1.1 \times 1.6 \times 1.1$ & 2.6 & Нуро & Hyper & NA & NA & $-3 \mathrm{~mm}$ & 74 & No & Headache, blurry vision \\
\hline 2 & M & $1.5 \mathrm{~T}$ & & $0.8 \times 0.9 \times 1.0$ & 5.8 & Нуро & Hyper & NA & Нypo & $\lambda$ & 58 & No & $\begin{array}{l}\text { Developmental delay, } \\
\text { initially called } \\
\text { dermoid }\end{array}$ \\
\hline 17 & $\mathrm{~F}$ & $1.5 T$ & $\mathrm{~T}$ & $1.3 \times 1.0 \times 1.0$ & 2.8 & Нуро & Hyper & Нуро & Нуро & $\lambda$ & 52 & Yes & Occipital headaches \\
\hline
\end{tabular}

Note:- Hypo indicates hypointense relative to brain; Iso, isointense relative to brain; Hyper, hyperintense relative to brain; Mixed, areas of hypointensity and isointensity on T1Wl; FS, magnetic field strength; Distance Above Torcular, linear distance above torcular; T, time-of-flight; C, elliptic centric encoded, contrast-enhanced MRV; SSS, superior sagittal sinus; M, male; F, female; NA, not applicable; MS, multiple sclerosis. Patient 10 did not have fluid-attenuated inversion recovery or diffusion-weighted MR imaging, and patient 11 did not have fluid-attenuated inversion recovery.

obtained in both axial and coronal planes at $1.5 \mathrm{~T}$ and $0.7 \mathrm{~T}$ by using 4-mm section thickness. At 3T, axial and coronal 3D fast-spoiled gradient (FSPGR) images (TE, minimum full; flip angle, $20^{\circ}$; $352 \times$ 224 matrix; $1.25-\mathrm{mm}$ section partition) were obtained after the administration of contrast. If CE-MRV was performed, postcontrast images were obtained by using the contrast dose listed below.

TOF-MRV was performed by using both axial and coronal imaging planes $\left(256 \times 128\right.$ matrix; flip angle, $\left.50^{\circ}\right)$. CE-MRV was performed using a modification of a previously reported elliptic centricordered high-resolution technique ${ }^{7}$ (spoiled gradient sequence; TR, $7.0 \mathrm{~ms}$; TE, minimum ( $1.3 \mathrm{~ms}$ ); flip angle, $35^{\circ}$; matrix, $320 \times 320$; FOV, $25 \mathrm{~cm}$; section thickness, $1.3 \mathrm{~mm}$; NEX, 1.0; bandwidth, 62.50 $\mathrm{kHz}$; elliptical centric encoding; imaging time, 3 minutes 24 seconds). Scanning was performed in the sagittal plane from ear to ear. A total of $30 \mathrm{~mL}$ of intravenous gadolinium was injected at rate of $3.0 \mathrm{~mL} / \mathrm{s}$ for this sequence. The MRV acquisition was initiated after a 10 -second delay after the bolus was detected in the cervical carotid arteries by MR fluoroscopy. CT imaging was performed at a section thickness of $5 \mathrm{~mm}$, with no intersection gap.

\section{Imaging Analysis}

Each case was evaluated carefully to assess size, signal intensity, morphology, enhancement, adjacent venous anatomy, calvarial morphology (inner table scalloping), sinus stenosis, location relative to the lambda (junction of the sagittal and lambdoid sutures), and linear distance from the center of the torcular herophili as measured on sagittal images. In selected cases more advanced reconstruction techniques were used using a 3D workstation (Vitrea 2; Vital Images, Minnetonka, Minn).

A literature search was performed using the search terms "arachnoid granulations" and "pacchionian granulations" in PubMed and Google Scholar to identify other reported cases. These reports were tabulated and compared with the current series (on-line Table 1). A tabulation of previous imaging and anatomic descriptions of AG was also made for assessment of the frequency of dorsal SSS AG (Table 2).

\section{Results}

An overview of the results is given in Table 1. There were 5 males and 7 females in the study group with an age range of 2-64 years of age (mean, 37 years). Eight patients presented with headaches, 1 patient was imaged to follow-up multiple sclerosis with new left leg weakness, 1 patient presented for evaluation of acute ischemic stroke, 1 presented with seizures secondary to a right frontal astrocytoma, and 1 presented for evaluation of developmental delay. In 1 patient with headache, there were findings consistent with a Chiari I malformation. In the other 7 patients with headache, no explanatory imaging findings were present. In 4 cases, the initial outside imaging interpretation of the large AG in the SSS was pathologic (thrombosis in 2 cases, meningioma in 1, and possible dermoid in another).

In all of the cases, a T2 hyperintense projection into the SSS was noted, similar to CSF signal intensity (Fig 1). On T1WI, 8 were hypointense, and 4 were hypointense with mixed areas of isointense signal intensity. On FLAIR imaging 7 were isointense, and 3 were hypointense ( 2 patients did not have FLAIR sequences performed). The signal intensity on DWI was hypointense relative to the brain (increased in signal intensity on apparent diffusion coefficient maps) in all 11 cases in which it was performed (Table 1).

Direct connectivity of the center of the AG could be identified with the subarachnoid space on FSE T2WI and highresolution CE T1WI (Fig 2). In 9 cases, internal flow voids or enhancing vessels could be identified (Figs 2 and 3). No masslike enhancement was noted. In all of the cases, a cortical vein could be identified entering the sinus directly adjacent to the AG (Figs 2 and 3).

The average size of the AG was $8.1 \times 9.4 \times 10.0 \mathrm{~mm}$ (range, 4-19 $\mathrm{mm}$ ). Average diameter stenosis of the SSS secondary to the $\mathrm{AG}$ was $57 \%$ (range, $20 \%-86 \%$ ). In 10 cases there was $50 \%$ or more diameter stenosis of the SSS lumen. On MRV, AGs appeared as focal well-defined defects, displacing and distort- 


\begin{tabular}{|c|c|c|c|c|c|c|c|c|c|c|c|c|c|}
\hline Reference & Modality & Patients & $\begin{array}{l}\text { Case } \\
\text { Type }\end{array}$ & No. & NOS & $\begin{array}{l}\text { Vent. } \\
\text { Sup. }\end{array}$ & $\begin{array}{l}\text { Dors. } \\
\text { Inf. }\end{array}$ & TS & SS & $\mathrm{TH}$ & StS & VoG & Notes \\
\hline Leach et $\mathrm{al}^{1}$ & CT with contrast & 573 & Unselected & 168 & NA & 0 & 1 & 154 & 3 & 8 & 2 & 0 & $\begin{array}{l}\text { 3- to 5-mm posterior fossa, } \\
\text { 10-mm supratentorial } \\
\text { section thickness }\end{array}$ \\
\hline Leach et al ${ }^{1}$ & MR with contrast & 100 & Unselected & 14 & NA & 0 & 1 & 13 & 0 & 0 & 0 & 0 & $\begin{array}{l}\text { 5- to } 6-m m \text { section } \\
\text { thickness }\end{array}$ \\
\hline Leach et $\mathrm{al}^{1}$ & Anatomic & 29 & Unselected & 91 & NA & NA & 0 & 86 & 0 & 5 & NA & NA & $\begin{array}{l}\text { Did not assess anterior } \\
\text { superior SSS, included } \\
\text { posterior inferior }\end{array}$ \\
\hline Roche et $\mathrm{al}^{3}$ & MR, CT, angiography & 32 & Selected & 42 & NA & 0 & 0 & 36 & 4 & 2 & 0 & 0 & Selected cases \\
\hline Liang et $\mathrm{al}^{4}$ & MR with contrast & 100 & Unselected & 433 & NA & 227 & 6 & 122 & 0 & 0 & 76 & 2 & $\begin{array}{l}\text { Assessed all dural sinuses, } \\
\text { 3D MPRAGE, 1.3-mm } \\
\text { section thickness }\end{array}$ \\
\hline Gailloud et al ${ }^{13}$ & Angiography & 57 & Unselected & 15 & NA & 0 & 2 & 12 & 0 & 1 & 0 & 0 & $\begin{array}{l}\text { All } 12 \text { TS AGs at vein of } \\
\text { Labbe entrance site, } \\
\text { angiographic study }\end{array}$ \\
\hline Browder et al ${ }^{6}$ & Anatomic & 295 & Unselected & 25 & NA & 0 & 2 & 23 & 0 & 0 & 0 & 0 & $\begin{array}{l}\text { Only counted large } \\
\text { protuberances }\end{array}$ \\
\hline |kushima et al ${ }^{19}$ & MR & 1118 & Unselected & 134 & 5 & NA & NA & 115 & 3 & 8 & 3 & 0 & Noncontrast MR \\
\hline Koshikawa et al ${ }^{20}$ & MR & 151 & Unselected & 162 & NA & NA & NA & 162 & NA & NA & NA & NA & TS only \\
\hline
\end{tabular}

Note:-TS indicates transverse sinus; SS, sigmoid sinus; TH, torcular herophili; StS, straight sinus; VoG, vein of Galen confluence with StS; Vent. Sup., ventral superior SSS; Dors. Inf., dorsal inferior SSS; NA, not applicable; AG, arachnoid granulation; MPRAGE, magnetization-prepared rapid acquisition of gradient echo; SSS, superior sagittal sinus; NOS, location not otherwise specified.

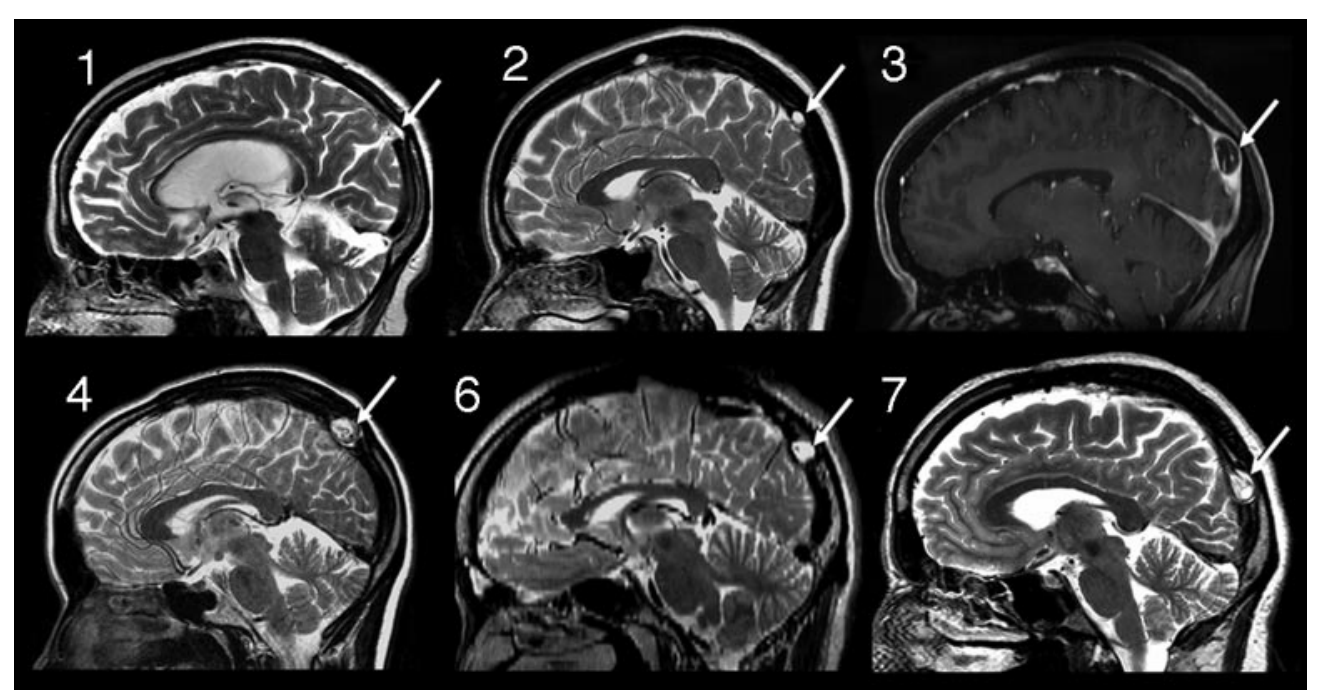

Fig 1. Sagittal images from cases 1,2 3, 4, 6, and 7 demonstrating the typical position of the dorsal SSS AG identified in this study (arrows). Case 3, Sagittal reconstruction of FSPGR postcontrast T1-weighted image (3T); case 6, sagittal reconstructed image from 2-mm axia FSE T2-WI (3T); all others, sagittal FSE T2-weighted images

ing the lumen of the sinus. In 6 cases, the AG was associated with septation of the SSS. Often multiple $(>2)$ distinct lumens were visible around the margin of the AG (Fig 3). Smooth remodeling of the inner table was noted related to the AG in 10 cases. In 5 cases, the remodeling was very prominent (Figs 1 and 2).

The average vertical distance of the AG from the torcular herophili was $46 \mathrm{~mm}$ (range, 26-62 mm). Eleven AGs were in the direct vicinity of the lambda, with 1 AG occurring $12 \mathrm{~mm}$ above the lambda. All of the AGs were within $3 \mathrm{~mm}$ of the level of the posterior margin of the parietal-occipital sulcus. The review of the literature identified 9 previously reported cases of large AGs in the dorsal SSS. None of these were described by 3T or high-resolution CE-MRV (on-line Table 1).

\section{Discussion}

In this report we described 12 cases of large AGs in the dorsal SSS, with the following imaging characteristics: CSF-like signal intensity, direct extension of the subarachnoid space into the granulation via a focal absence or rent in the sinus dural margin, intrinsic vessels (presumed to be displaced cortical venous structures or sinus septations), identification of directly adjacent cortical veins, and typical location (near the lambda, at the level of the posterior margin of the parietooccipital sulcus). None were bright on FLAIR, and there was no diffusion restriction or intrinsic masslike enhancement. This morphology closely resembles previous case reports of this entity. ${ }^{1,5,8}$ The signal intensity of AGs in this study was isointense to brain in 7 of 10 of the cases in which FLAIR sequences were performed. In each case, CSF in the subarachnoid space was more hypointense. This may be due to pulsation artifact from the adjacent sinus and differing CSF flow characteristics within the granulation.

The finding of intrinsic vessels within large AGs (presumably displaced veins within the granulation or sinus channels) has been described previously. In case 2 described by Mamourian and Towfighi, ${ }^{5}$ a note of linear low signal intensity crossing the dura into the AG pedicle is made, similar to 


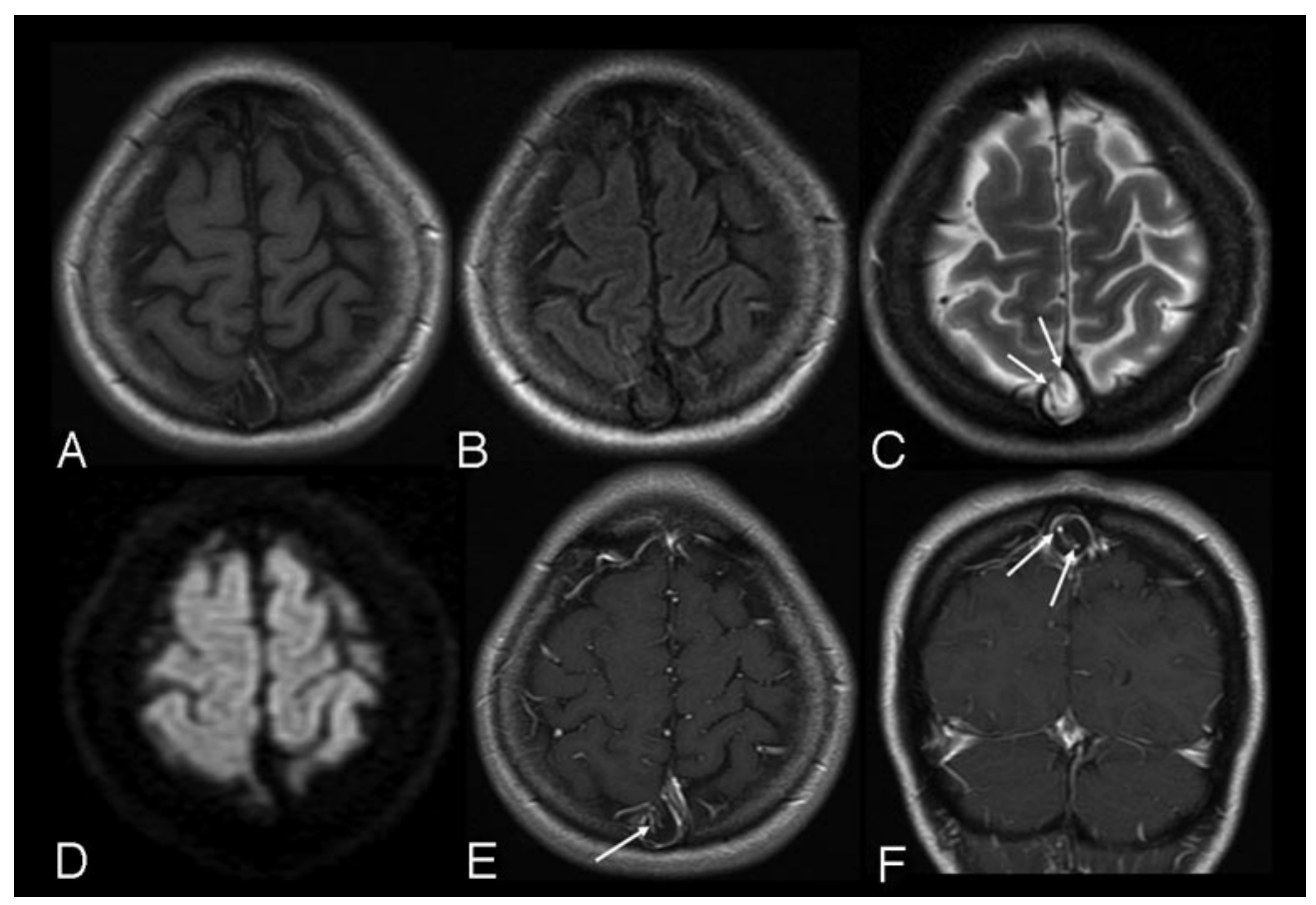

Fig 2. Case 4, 1.5T, axial T1WI $(A)$ FLAIR $(B)$, T2WI (C), DWI (D), and postcontrast T1WI (E and F). Typical appearance on multiple pulse sequences. Note the large AG with associated defect in the dura (arrows, C) along the rightward margin of the SSS. Note intrinsic vessels, which appear to be displaced cortical veins or channels (arrows, $E$ and $F$ ). There is focal calvarial remodeling.

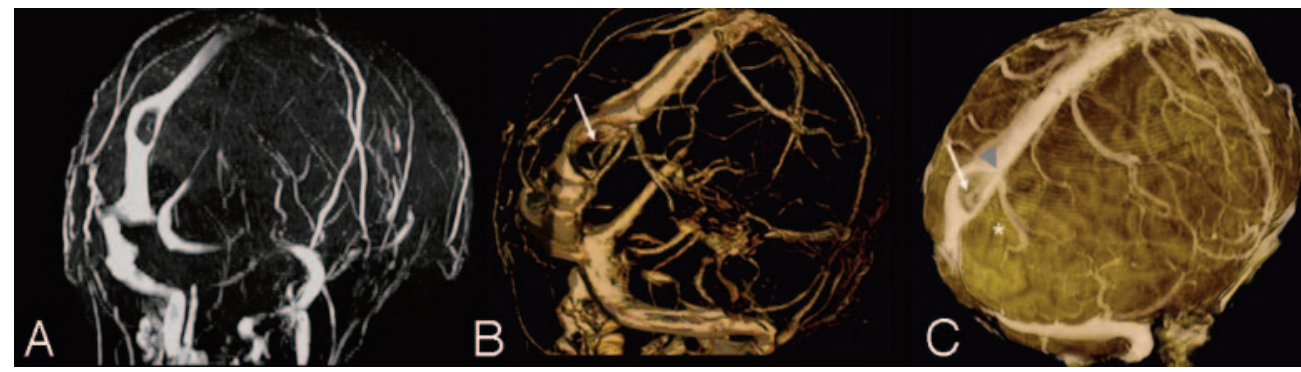

Fig 3. Case 3, 3T. Axial acquired TOF$\operatorname{MRV}(A)$, CE-MRV $(B)$, and segmented volume-rendered FSPGR sequence after contrast $(C)$.Note multilumen SSS, intrinsic vessels (arrows, $B$ and $C$ ), thin AG base along the SSS (arrowhead, C), and adjacent cortical vein $\left({ }^{*} \mathrm{C}\right)$.

the intrinsic vessels seen in our cases. In the contrast-enhanced CT images in the article published by Kan et al, ${ }^{9}$ intrinsic vessels within the granulation are also well seen, though not described in the text. In a report by Chin et al, ${ }^{10}$ demonstration of internal flow voids was identified in a left TS AG, compatible with venous channels. Farb ${ }^{11}$ describes a displaced eccentric internal vein in $97 \%$ of AGs greater than $4 \mathrm{~mm}$ in diameter by using high-resolution CE-MRV. This finding should be used as strong supporting evidence for the diagnosis of AGs.

A characteristic location of the granulations was shown in our study $(2.6-6.0 \mathrm{~cm}$ above the torcular, near the lambda and posterior aspect of the parieto-occipital sulcus). Evaluating previous reports also demonstrates a similar position in most of the reported cases. ${ }^{1,5,6,8,9}$ Browder et $\mathrm{al}^{6}$ described 2 AGs in the dorsal SSS at 4.5 and $6.0 \mathrm{~cm}$ above the torcular. The primitive falcine sinus terminates near this position. ${ }^{12}$ It may be that a relative weakening in the dura may be left as the sinus involutes, allowing the formation of larger-than-normal AG at this position during further development. The entry of cortical veins adjacent to the AG could also produce a potential weakening in the sinus wall as the vessel enters the sinus, allowing for displacement of subarachnoid space and adjacent vessels into the sinus lumen. ${ }^{13}$

Calvarial remodeling is common with AGs of the SSS or lateral lacunae ${ }^{14}$ and has also been described with those adjacent to the TS and temporal bone. ${ }^{15,16}$ In 10 of our cases, smooth calvarial remodeling was noted, in 5 cases to a marked degree. This has also been demonstrated in previous reports of dorsal SSS AGs. ${ }^{1,5,8,9}$ Septations in the SSS were noted in 4 of our cases, adjacent to or involving the region of the AG. This has also been documented ${ }^{9}$ and suggested ${ }^{5}$ in other reports.

Most published images of SSS AG in this region are large $(\geq 10 \mathrm{~mm}),{ }^{1,5,8,9,13}$ as contrasted with a smaller size in the TS and SSS. ${ }^{1,4}$ Of dorsal SSS AG cases described in the literature with reported measurements, maximal dimensions are between 4 and $24 \mathrm{~mm}$ (average, $12 \mathrm{~mm}$; current 12 cases in addition to 4 previous cases with measurements). This is significantly larger than the average size of AGs in general reported in previous studies $(4-5 \mathrm{~mm})$ in which most AGs were measured in the TS and anterior SSS. ${ }^{1,3,4}$ Although in part this may be related to selection and reporting bias, review of careful anatomic and imaging studies ${ }^{1,4}$ supports that, when AGs occur in the dorsal SSS, they may indeed be larger.

Despite the prevalence of AGs visible in the dural sinuses on imaging studies, ${ }^{4}$ AGs in the dorsal SSS have been reported rarely. Compilation of the literature on AG location identified by imaging and anatomic assessment is given in Table 2. Evaluating imaging studies by using both noncontrast and contrast-enhanced techniques and unselected patients ${ }^{1,4}$ gives a prevalence of dorsal SSS AG of $1(0.17 \%)$ of 573 by CT ${ }^{1}$ and 7 (3.50\%) of 200 by MR. ${ }^{1,4}$ By anatomic assessment, prevalence 
is $2(0.6 \%)$ of $324 .^{1,6}$ This is much less than the reported prevalence of AGs in the TS (as high as $69 \%$ of patients). ${ }^{4}$

Relationship to patient symptoms is uncertain. Symptoms have been ascribed to large AGs in previous reports ${ }^{17}$; however, most are probably asymptomatic and should be regarded as a normal variant. In 7 of our patients with headache, no other imaging-identified cause of headache was elucidated. In 1 case of large dorsal SSS AGs in a patient with headache, Kan et $\mathrm{al}^{9}$ performed intrasinus manometry within the septated venous channels around the AG and found no evidence of a pressure differential. In an additional patient with a focally depressed skull fracture directly impacting and severely stenosing the posterior SSS without thrombosis, clinical presentation with headache and the intracranial hypertension syndrome was present resolving with fracture elevation and resolution of SSS stenosis. ${ }^{18}$ This report documents that SSS stenosis in this region can be symptomatic.

Differentiation from other pathology is important, as evidenced by the 4 cases in our series originally called thrombosis or tumor. If not correctly diagnosed, inappropriate therapy (anticoagulation or surgery) may have occurred in these patients. Differential diagnostic considerations for a mass in this area include meningioma, dermoid, and epidermoid. The imaging characteristics in our cases are not compatible with these diagnoses. No fat signal intensity or attenuation is noted to suggest dermoid, no diffusion restriction to suggest epidermoid, and no enhancement to suggest neoplasm, such as meningioma, were present.

The major limitation to our study is that it is a retrospective review of identified cases by 1 group resulting in selection bias for AGs in this region. This is not a population-based study, so comment as to the true (or relative) incidence cannot be made. Although the finding of 12 sequential cases of large AGs in a stereotypical location in the dorsal SSS is intriguing (particularly given the similar locations of previously reported cases), any further discussion of a common developmental etiology is speculative (as detailed above). Another limitation is the lack of pathologic correlation. The AGs in our study closely match previous reported cases, and the imaging findings are consistent with previous pathologic descriptions. The point of emphasis is that large AGs can occur in this position and may be mistaken for other pathology, but a careful analysis of imaging characteristics should lead to the correct diagnosis.

\section{Conclusion}

Large AGs in the dorsal SSS occur rarely but can be mistaken for pathology. Imaging features include CSF-like signal intensity, identification of direct extension of the subarachnoid space into the granulation, focal absence or rent in the sinus dural margin, intrinsic vessels or channels, identification of directly adjacent cortical veins, typical location near the lambda, calvarial remodeling when large, and associated SSS septation or duplication. The characteristic location of dorsal SSS AG in this series and other reported cases suggests a common developmental etiology. Although commonly causing sinus stenosis, the relationship to patient symptoms remains uncertain.

\section{References}

1. Leach JL, Jones BV, Tomsick TA, et al. Normal appearance of arachnoid granulations on contrast-enhanced CT and MR of the brain: differentiation from dural sinus disease. AJNR Am J Neuroradiol 1996;17:1523-32

2. Leach JL, Fortuna RB, Gaskill-Shipley MG, et al. Imaging of cerebral venous thrombosis. Current techniques, imaging spectrum, diagnostic pitfalls. $R a$ dioGraphics 2006;26:S19-43

3. Roche J, Warner D. Arachnoid granulations in the transverse and sigmoid sinuses: CT, MR, and MR angiographic appearance of a normal anatomic variation. AJNR Am J Neuroradiol 1996;17:677-83

4. Liang L, Korogi Y, Sugahara T, et al. Normal structures in the intracranial dural sinuses: delineation with $3 \mathrm{D}$ contrast-enhanced magnetization prepared rapid acquisition gradient-echo imaging sequence. AJNR Am J Neuroradiol 2002;23:1739-46

5. Mamourian AC, Towfighi J. MR of giant arachnoid granulations: a normal variant presenting as a mass within the dual venous sinus. AJNR Am J Neuroradiol 1995; 16:901-04

6. Browder J, Browder A, Kaplan HA. Benign tumors of the cerebral dural sinuses. J Neurosurg 1972;37:576-79

7. Farb RI, Scott JN, Willinsky RA, et al. Intracranial venous system: gadoliniumenhanced three-dimensional MR venography with auto-triggered elliptic centric-ordered sequence-initial experience. Radiology 2003;226:203-09

8. Cure JK, Van Tassel P, Smith TM. Normal and variant anatomy of the dural venous sinuses. Semin Ultrasound CT MR 1994;15:499-519

9. Kan P, Stevens EA, Couldwell WT. Incidental giant arachnoid granulation. AJNR Am J Neuroradiol 2006;27:1491-92

10. Chin SC, Chen CY, Lee CC, et al. Giant arachnoid granulation mimicking dural sinus thrombosis in a boy with headache: MRI. Neuroradiology 1998;40:181-83

11. Farb RL. The dural venous sinuses: normal intraluminal architecture defined on contrast-enhanced MR venography. Neuroradiology 2007;49:727-32

12. Strub WM, Leach JL, Tomsick TA. Persistent falcine sinus in an adult: demonstration by MR venography. AJNR Am J Neuroradiol 2005;26:750-51

13. Gailloud P, Muster M, Khaw N, et al. Anatomic relationship between arachnoid granulations in the transverse sinus and the termination of the vein of Labbe': an angiographic study. Neuroradiology 2001;43:139-43

14. Grossman CB, Potts DG. Arachnoid granulations: radiology and anatomy. Radiology 1974;113:95-100

15. VandeVyer V, Lemmerling M, De Foer B, et al. Arachnoid granulations of the posterior temporal bone wall: imaging appearance and differential diagnosis. AJNR Am J Neuroradiol 2007;28:610-12

16. Branan R, Wilson CB. Arachnoid granulations simulating osteolytic lesions of the calvarium. AJR Am J Roentgenol 1976;127:523-25

17. Arjona A, Delgado F, Fernandez-Romero E. Intracranial hypertension secondary to giant arachnoid granulations. J Neurol Neurosurg Psychiatry 2003;74:418

18. Hiroshi Y, Takahiko E, Nobayashi M, et al. Persistent intracranial hypertension caused by superior sagittal sinus stenosis following depressed skull fracture. Case report and review of the literature. J Neurosurg 2006;104:849-52

19. Ikushima I, Korogi $\mathrm{Y}$, Makita $\mathrm{O}$, et al. MRI of arachnoid granulations within the dural sinuses using a FLAIR pulse sequence. Br J Rad 1999;72:1046-51

20. Koshikawa T, Naganawa S, Fukatsu H, et al. arachnoid granulations on highresolution MR images and diffusion-weighted MR images: normal appearance and frequency. Radiat Med 2000;18:187-91 